\title{
EL PENSAMIENTO CRÍTICO Y SU INCIDENCIA EN LA EDUCACIÓN DE LAS ARTES PLÁSTICAS: CASO IE BOJACÁ DE CHÍA, COLOMBIA ${ }^{1}$
}

\author{
Ernesto Fajardo Pascagaza ${ }^{2}$ \\ Edna Lilian Castellanos Avellaneda ${ }^{3}$
}

Resumen: El presente artículo es producto de la investigación realizada en la IE Bojacá de Chía, Colombia en torno al pensamiento crítico y su incidencia en la educación de las artes plásticas. En esta institución se adolece de profesionales idóneos para formar en esta área del conocimiento lo cual ha generado dificultades cognitivas y actitudinales en los estudiantes en torno a su formación artística, especialmente en cuanto al desarrollo de habilidades de pensamiento crítico. Para tal efecto, y buscando responder a esta realidad educativa actual, se propone el diseño de una estrategia de enseñanza que contribuya al desarrollo del pensamiento crítico desde la educación en artes plásticas a partir de la lectura de imágenes visuales. El proyecto se realiza desde un paradigma interpretativo, con un enfoque histórico hermenéutico, de tipo cualitativo y diseño fenomenológico desde la caracterización del uso de las habilidades de pensamiento crítico con la lectura de imágenes visuales y a partir de estos resultados se elabora la estrategia de enseńanza. La propuesta se centra en el trabajo de las habilidades de interpretación, análisis, inferencia y evaluación así como la realización de trabajo transversal con el área de lengua castellana para mejorar la presentación de los resultados.

Palabras clave: Educación artística, artes plásticas, pensamiento crítico.

1 Artículo producto de la investigación realizada al interior del Grupo de Investigación ALETHEIA de la Universidad Santo Tomás, en torno a la relación entre educación, ética y política

2 Doctorando en Educación, Doctorando en Filosofía, Magíster en Filosofía y Magíster en Educación. Docente del Departamento de Humanidades y Formación Integral de la USTA. Integrante del Grupo de Investigación ALETHEIA. Investigador principal. Correo electrónico: ernestofajardo@usantotomas.edu.co

3 Magister en Educación. Especialista en fotografía. Maestra en artes plásticas. Universidad Nacional de Colombia. Docente de educación artística. edna.castellanos@yahoo.com 


\title{
CRITICAL THINKING AND ITS IMPACT ON THE EDUCATION OF PLASTIC ARTS: CASE IE BOJACÁ DE CHÍA, COLOMBIA
}

\begin{abstract}
This article is a product of the research carried out at EI Bojacá de Chía, Colombia on critical thinking and its impact on the education of plastic arts. This institution suffers from qualified professionals to train in this area of knowledge which has generated cognitive and attitudinal difficulties in students around their artistic training and especially in the development of their critical thinking skills. To this end, and seeking to respond to this current educational reality, the design of a teaching strategy that contributes to the development of critical thinking from education in plastic arts from the reading of visual images is proposed. The project is carried out from an interpretive paradigm, with a hermeneutical historical approach, of a qualitative type and phenomenological design from the characterization of the use of critical thinking skills with the reading of visual images and from these results the teaching strategy is elaborated. The proposal focuses on the work of interpretation, analysis, inference and evaluation skills as well as cross-sectional work with the Spanish language area to improve the presentation of the results.
\end{abstract}

Keywords: Art education, plastic arts, critical thinking.

\section{O PENSAMENTO CRÍTICO E SUA INCIDÊNCIA NA EDUCAÇÃO DE ARTES PLÁSTICAS: CASO I BOJACÁ DE CHÍA, COLÔMBIA}

\begin{abstract}
Resumo: Este artigo é um produto da pesquisa realizada em EI Bojacá de Chía, Colômbia, sobre pensamento crítico e seu impacto no ensino de artes plásticas. Esta instituição sofre com profissionais qualificados para treinar nesta área de conhecimento, o que gerou dificuldades cognitivas e de atitude nos alunos em torno de sua formação artística e, principalmente, no desenvolvimento de suas habilidades de pensamento crítico. Para tanto, e buscando responder a essa realidade educacional atual, propóe-se o desenho de uma estratégia de ensino que contribua para o desenvolvimento do pensamento crítico da educação em artes plásticas a partir da leitura de imagens visuais. O projeto é realizado a partir de um paradigma interpretativo, com abordagem histórica hermenêutica, de tipo qualitativo e desenho fenomenológico, a partir da caracterização do uso de habilidades de pensamento crítico com a leitura de imagens visuais e a partir desses resultados é elaborada a estratégia de ensino. A proposta concentra-se no trabalho de habilidades de interpretação, análise, inferência e avaliação, bem como trabalho transversal com a área de língua espanhola para melhorar a apresentaçáo dos resultados.
\end{abstract}

Palavras-chave: Educação artística, artes plásticas, pensamento crítico.

\section{Introducción}

Las artes, las ciencias y la filosofía surgen de la profunda esencia del hombre, de la necesidad que tiene de adquirir nuevos conocimientos, de crear obras, de transformar su entorno y de comunicar lo que ha aprendido. Las formas de expresión humana como el arte, surgen cuando las palabras y la complejidad de la existencia no bastan para manifestar lo sublime y trascendente de la realidad del hombre. Por medio del lenguaje de las artes se ha escrito la historia de la humanidad 
y sus costumbres, sus sueños y utopías, sus logros y también sus fracasos, pero ante todo, el origen de la conciencia por la armonía, por la creación de nuevas obras expresadas estéticamente.

Las comprensiones que hay sobre el arte se expresan en la comunidad educativa y por consiguiente, influyen significativamente en la formación integral de los educandos. El objetivo de enseñar a pensar (y) es el de preparar a los estudiantes para que resuelvan los problemas de la cotidianidad y aporten a la resolución de los eventos problémicos de su entorno vital de manera crítica, creativa y ética. El arte en la academia, en la escuela, es una oportunidad privilegiada para canalizar talentos y abrir horizontes de comprensión hacia el pensamiento holístico, hacia la creatividad y el desarrollo cognitivo.

El arte y su lenguaje de lo estético, van más allá de la razón permitiendo que el hombre desde la imaginación se exprese significativamente desde la singularidad y lo universal a la vez. En este sentido, la escuela ha de orientar la práctica pedagógica hacia la interpretación de las expresiones de arte y lo sublime de sus obras. El conocimiento y reflexión de lo artístico desde el contexto de lo educativo, es un proceso que trasciende la historia de la humanidad y se hace vivencial en la cotidianidad práxica de los ambientes escolares que son matizados desde lo global pero que se evidencian en lo local, como es el caso de las propuestas educativas colombianas y en contextos específicos como la Institución Educativa de Bojacá.

En la IE Bojacá de Chía, Colombia, se encontró que la clase de educación artística con énfasis en artes plásticas se ha visto afectada por situaciones como la falta de docentes con el perfil adecuado y los imaginarios sobre la educación artística como un proceso de formación manual y técnico. Frente a esta dificultad, los estudiantes no han tenido una formación en arte que les permita desarrollar habilidades de pensamiento como la reflexión o el análisis.

Para contrarrestar esta falencia y proponer una educación acorde a las necesidades educativas actuales, se propone el diseño de una estrategia de enseñanza que contribuya al desarrollo del pensamiento crítico desde la educación en artes plásticas, y el camino para cumplir este objetivo se propone desde la formación en lectura de imágenes visuales.

El proyecto se realiza desde un paradigma interpretativo, con un enfoque histórico hermenéutico, de tipo cualitativo y diseño fenomenológico. En un primer momento se realiza una caracterización del uso de las habilidades de pensamiento crítico desde la lectura de imágenes visuales y a partir de estos resultados se elabora la estrategia de enseńanza. Como parte de la caracterización, los estudiantes identificaron la información visual principal lo cual se hizo con escasa la reflexión y pocos acudieron a otras fuentes de información para verificar la veracidad de la imagen. La propuesta se centra en el trabajo de las habilidades de interpretación, análisis, inferencia, evaluación y la realización de trabajo transversal con el área de lengua castellana para mejorar la presentación de los resultados. 


\section{La formación artística en el contexto de la IE Bojacá.}

Para construir el problema de esta investigación se parte de dos dificultades que convergen en el área de la educación artística con énfasis en artes plásticas de la IE Bojacá, por una parte, la orientación técnica de las clases arte y por otra, la asimilación pasiva por parte de los estudiantes de las imágenes que los circundan.

Respecto a la primera dificultad, para el 2018, la malla curricular de artes plásticas de la IE Bojacá para educación básica secundaria y media vocacional, se concentra en la enseñanza de aspectos formales de las artes visuales. Inicia en grado sexto y termina en grado once pasando por temáticas como el punto, la línea, la letra script, la técnica de carboncillo y la técnica del óleo entre otras.

En este orden, durante los últimos años, la institución no había contado con un docente con formación profesional en el área artística. Por el contrario, la responsabilidad de esta asignatura fue asumida por profesores de otras áreas del conocimiento y según entrevistas realizadas a estudiantes de la formación media vocacional, las clases se centraron en actividades como la realización de círculos cromáticos y el tejido a dos agujas.

Si bien es un intento aportar a la formación del estudiante, esta concepción de la educación artística corresponde a un imaginario anacrónico. El conocimiento de la teoría del color y el uso de herramientas de dibujo son útiles para la expresión plástica pero no llegan a constitur el fin último de la formación. La enseñanza de las artes plásticas y visuales necesita de herramientas técnicas sin limitarse solamente a éstas. Como lo señala Acaso (2009),

Hoy en día hay que reivindicar la enseñanza de las artes y la cultura visual como un área relacionada con el conocimiento, con el intelecto, con los procesos mentales y no solo manuales, con enseńar a ver y a hacer con la cabeza y las manos y no solo enseñar a hacer con las manos (pp. 17-18)

Esta percepción permite determinar que la mayor parte de los estudiantes reproducen imágenes e información de su entorno literal de manera mecánica, sin una reflexión aparente sobre el sentido de las imágenes reproducidas. Esta reproducción mecánica y acrítica de las imágenes circundantes es coherente con una educación en arte que no ha brindado elementos de análisis visual ni herramientas para que cada estudiante se relacione con su entorno de un modo crítico, pasando por el filtro de la crítica, (Habermas, 1989), y lo creativo. Los estudiantes están reproduciendo lo que ven sin mediar preguntas para sí mismos.

Este analfabetismo visual pone en desventaja al estudiante ya que dicho lenguaje presenta un ascenso vertiginoso a causa de los adelantos tecnológicos desarrollados en los últimos siglos. Desde la imprenta hasta los teléfonos celulares, pasando por la televisión, el internet y las cámaras digitales. La información visual que recibimos en la actualidad es mayor que en otras épocas, se reproduce velozmente y en muchos casos, a bajo costo.

En un tiempo en el que los desarrollos tecnológicos surgen de manera vertiginosa, las comunicaciones cada vez son más ágiles y abundantes, y, por lo tanto, 
los jóvenes no reparan en las imágenes que consumen debido al ritmo acelerado de su producción. El lenguaje visual ofrece grandes facilidades para comunicarse en el mundo globalizado. Este lenguaje trasciende fronteras idiomáticas, permite una lectura casi inmediata, se multiplica rápidamente y es de fácil acceso. Aunque se envía masivamente, se dirige a cada individuo impregnando los sentidos, el intelecto y las emociones del observador desprevenido.

Algunos contenidos de este mar informativo quedarán reservados solo para observadores atentos mientras que otros se asimilan de manera inconsciente. Pero jóvenes y adultos están expuestos a procesos de colonización y aculturación visual. Por lo mismo, se hace vital educar para pensar el mundo que se habita y desarrollar competencias coherentes con el mismo.

En la actualidad, el observador que no cuenta con habilidades para leer e interpretar la información que recibe, sea cual sea su forma (fotografías, cine, textos, periódicos o noticieros entre otros), se encuentra en una posición vulnerable frente a la multiplicidad de discursos emitidos por las fuentes de información que unas veces bombardean y otras (fo) seducen. La humanidad no se había enfrentado a una proliferación tan acelerada de desarrollos tecnológicos e informativos como se vive hoy. Y es en este sentido que la educación cuenta con un gran reto por delante. Para Bauman (2007):

En ningún otro punto de inflexión de la historia humana los educadores debieron afrontar un desafío estrictamente comparable con el que nos presenta la divisoria de aguas contemporánea. Sencillamente, nunca antes estuvimos en una situación semejante. Aún debemos aprender el arte de vivir en un mundo sobresaturado de información. Y también debemos aprender el aún más difícil arte de preparar a las próximas generaciones para vivir semejante mundo. (p. 46)

De las situaciones mencionadas: los avances tecnológicos acelerados, la difusión precipitada de la información, el auge del lenguaje visual y el analfabetismo visual, se desprende la necesidad de una educación artística pertinente y que realmente corresponda a las necesidades actuales de aprendizaje de los estudiantes.

Entre las habilidades más mencionadas que necesitan desarrollar los jóvenes del siglo XXI, se encuentra el pensamiento crítico, (Peeler, 2016), y la capacidad para relacionarse con información, en este caso, visual. Esto último, aunque no es exclusivo, si le compete a la educación artística, es importante y necesario que contribuya al desarrollo de la capacidad crítica de los estudiantes. Por otra parte, ha de brindar herramientas que fomenten la capacidad de reflexión y criticidad de los jóvenes mientras se relacionan con un mundo en el cual se produce y circula información visual precipitadamente. Esta contribución desde la educación artística es vital como lo afirma Nussbaum (2010), para mantener viva la democracia en medio de un modelo económico global que busca terminar con esta.

¿Por qué investigación en educación artística y por qué el pensamiento crítico? Aunque el modelo económico global propende por una educación básica y media libre de conocimientos inútiles, centrada en el desarrollo de aptitudes que 
favorezcan el desarrollo económico de las naciones, se hace necesario equilibrar la balanza y contribuir a la formación de ciudadanos autónomos, críticos, (Morales, 2014), y humanos que aporten a la superación de brechas económicas entre países; ciudadanos que busquen la igualdad social, conscientes del cuidado del planeta, capaces de amar y cuidar a sus semejantes.

Aunque en las últimas décadas el arte ha sido rescatado por la economía como una disciplina que ejercita la creatividad y junto con ella la creación de empresas, la generación de ideas innovadoras y económicamente productivas, es necesraio tener presente que no es este el espíritu del arte. La creatividad y la innovación en la industria cultural corresponde más a una instrumentalización del trabajo artístico que a su fin.

Según Martha Nussbaum (2010), el modelo económico actual presiona sin compasión al sistema educativo para obtener sujetos útiles al sistema económico y como consecuencia, la educación se está transformando para suplir estas necesidades. Pero no lo ha hecho por convicción, lo ha hecho por presión del contexto. Lo anterior implica que las formaciones más valoradas por su capacidad para generar ingresos económicos como la tecnología o las ciencias exactas desplacen áreas enfocadas en el conocimiento social y artístico como la filosofía, la sociologia, la literatura, la pintura o la danza por poner algunos ejemplos.

Al generar dicho desplazamiento, Nussbaum (2010) afirma que también se eliminan aptitudes que mantienen viva la democracia. Sin educación artística el hombre se convierte en un instrumento al servicio de la economía, así que hace un llamado a rescatar las artes y las humanidades poniendo de manifiesto las bondades que estas conllevan para la humanidad: el pensamiento crítico, la imaginación y la compasión.

Para la escuela y para la sociedad constituye un desafío educar individuos capaces de enfrentar los retos propuestos por el mundo actual en pro de fomentar el desarrollo de sociedades democráticas que atiendan a fines más humanos y compasivos que el interés económico.

Además de Nussbaum, Luna (2015) en su escrito de la UNESCO, también señala la necesidad de formar estudiantes con pensamiento crítico como herramienta para el desenvolvimiento en el siglo XXI.

Por los motivos anteriores, este proyecto considera de vital importancia fomentar el pensamiento crítico de los jóvenes. Habitualmente se asocia el pensamiento crítico a las humanidades pero la imagen es un medio creciente en la actualidad y educar tanto en su lectura como en su producción es responsabilidad de la educación artística.

Así mismo, la educación artística de la IE Bojacá y su racionalidad perceptual (Mejía, 2008) necesitan trazar un nuevo rumbo más coherente con las necesidades de la sociedad actual.

Las clases de arte no pueden seguir vinculándose solamente a la pericia en ejecutar habilidades técnicas o en reproducir la naturaleza fielmente como sucedió 
en otros momentos de la historia del arte. La disciplina artística, la educación y el contexto del sistema educativo demandan un abordaje de la educación en arte desde otras perspectivas como la cultural, la cognitiva o la creativa (Mejía, 2008).

Para esta investigación se respondió a la pregunta por el diseño de una estrategia de enseñanza capaz de fortalecer el pensamiento crítico a partir del lenguaje visual en el aula de arte y en el trabajo con jóvenes de 15 a 17 años de edad que cursan grado décimo. Como objetivo general se tuvo el diseño de la estrategia de enseñanza pasando por tres momentos posteriores a la identificación del problema y su justificación: la descripción del uso de las habilidades del pensamiento crítico, (Parra, 2003), en la lectura de imágenes visuales, el establecimiento de una estrategia de enseñanza pertinente para el problema planteado y el diseńo de la estrategia propiamente dicha.

Los referentes teóricos que sustentan el proyecto corresponden a las habilidades de pensamiento crítico descritas por Facione en lo que se conoce como el Critical thinking, el concepto de zona de desarrollo próximo y el desarrollo sociocultural de Lev Vygotsky, las orientaciones dadas por el Ministerio de Educación de Colombia y la reflexión sobre el estudio de la cultura visual de Fernando Hernández.

El pensamiento crítico se rastreó como una forma de pensamiento que si bien no es exclusiva de la Escuela de Frankfurt ni de la Teoría crítica de la sociedad, si se consolida y formaliza como forma de pensamiento en este punto de la historia.

El pensamiento critico, es una forma de pensar responsable relacionada con
la capacidad de emitir buenos juicios. Es una forma de pensar de quien está
genuinamente interesado en obtener conocimiento y en buscar la verdad y
no simplemente en salir victorioso cuando se está argumentando. (González,
2006, p. 27)

Así mismo, Theodor Adorno acude al pensamiento crítico como la forma de prevenir la repetición del genocidio de Auschwitz, hecho que obligó a su generación conocer el lado más oscuro de la humanidad y el horror de la guerra. Este legado de responsabilidad que existe no solo es para los países donde se vivió el holocausto ni es exclusivo para determinadas formas de violencia. Es una responsabilidad extensiva a cualquier país y a cualquier tipo de violencia o pensamiento totalitario. En palabras de Adorno (1998),

Cuando hablo de la educación después de Auschwitz hablo de dos ámbitos: en primer lugar, educación en la infancia, sobre todo en la primera; seguidamente, ilustración general llamada a crear un clima espiritual, cultural y social que no permita una repetición; un clima, pues, en el que los motivos que llevaron al horror se hayan hecho en cierto modo conscientes. No pretendo, como es lógico, esbozar el plan de una educación de este tipo, ni siquiera en líneas generales. Pero sí quisiera caracterizar al menos algunos puntos neurálgicos. Con frecuencia se ha responsabilizado —en los Estados Unidos, por ejemplo - al espíritu alemán, tan dócil a la autoridad, del nacionalsocialismo y, por tanto, de Auschwitz. Considero esta explicación demasiado superficial, aunque entre nosotros, como en muchos otros países europeos, los comportamientos autoritarios y la autoridad ciega sobreviven, ciertamente, mucho más tenazmente de lo que parece aceptable en condiciones 
de democracia formal. Hay que asumir más bien que el fascismo y el terror que alentó guardan una íntima relación con la decadencia de los viejos poderes establecidos del Imperio, que fueron derrocados y abatidos antes de que las personas estuviesen psicológicamente preparadas para determinarse a sí mismas. No se mostraron a la altura de la libertad que les cayó del cielo. De ahí que las estructuras de la autoridad asumieran esa dimensión destructiva y - por así decirlo- demencial que antes no tenían o, cuanto menos, no mostraban. Si se piensa cómo la visita de tales o cuales soberanos carentes ya de toda función política efectiva hace entrar aún en éxtasis a poblaciones enteras, se verá hasta qué punto está perfectamente fundada la sospecha de que el potencial autoritario es, hoy como ayer, mucho más fuerte de lo que cabría imaginarse. (p. 81 y 82)

En un principio el estudio del pensamiento crítico viajó por Europa y al continente americano a causa de los intelectuales refugiados. Ahora, con la facilidad de las comunicaciones se hace de fácil acceso. En Norteamérica se consolidó el estudio de las disposiciones y habilidades de pensamiento crítico desde estudios psicológicos liderados por Facione y de donde se han tomado las habilidades a trabajar: la interpretación, el análisis, la inferencia, la evaluación, la explicación y la autocorrección.

Al definir la estrategia de enseñanza que se utilizaría en el desarrollo de las habilidades de pensamiento mencionadas, se vincula el trabajo de Lev Vygotsky y el desarrollo sociocultural del pensamiento. Para Vigotsky (1995),

el desarrollo del pensamiento está determinado por el lenguaje, es decir, por las herramientas lingüísticas del pensamiento y la experiencia socio-cultural del niño. Esencialmente, el desarrollo del lenguaje interiorizado depende de factores externos; el desarrollo de la lógica en el niño, como lo han demostrado los estudios de Piaget, es una función directa del lenguaje socializado. El crecimiento intelectual del nińo depende del dominio de los medios sociales del pensamiento, esto es, del lenguaje. (p. 44)

En este sentido, las imagenes constituyen un elemento del entorno visual y cultural del individuo e inciden en su desarrollo, así como lo hacen otras formas de lenguaje. La relación que se da en el desarrollo sociocultural del sujeto lo incluye a sí mismo, a la imagen y al ambiente contextual, modificandose mutua y dialecticamente.

El aprendizaje se encuentra determinado por la ubicación y las condiciones donde este se da. En este sentido no es igual relacionarse con un daguerrotipo del siglo XIX que con una fotografía del siglo XXI. Al establecer esta relación con el entorno, el docente tiene un papel de facilitador, en este caso, facilitar el acercamiento critico al mundo visual, intentando mantener activo el discernimiento frente a lo observado. Adorno mantiene muy presente el cambio cultural que se da con la aparición de las industrias culturales como un mecanismo de aparente integración y de apaciguamiento de los individuos en pro de un sistema económico.

Por lo tanto, destaca la importancia de educar no solo en el pensamiento crítico sino en campos específicos, complejos y vigentes como la industria y la 
comunicación visual. Si bien la siguiente reflexión tiene por objeto específico la televisión, es posible extenderla al interés general del proyecto, la criticidad frente a la imagen en un sentido más amplio. Según Adorno (1998),

...cómo hay que ver la televisión para no dejarse engañar, esto es, sin sucumbir a la televisión como ideología. Con otras palabras: la enseñanza que ha propuesto Ud. en el coloquio sobre estos medios no debería proponerse sólo capacitar a los espectadores para elegir lo adecuado, sino que debería desarrollar de entrada sus capacidades críticas; debería poner a las personas en condiciones de desenmascarar ideologías, por ejemplo; debería ponerlas al resguardo de identificaciones falsas y problemáticas, y debería, sobre todo, protegerlas de esa propaganda general a favor del mundo que viene ya inmediatamente dada por la simple forma de estos medios, con anterioridad a todo contenido. (p. 52 y 53$)$

En este sentido, la invitación a involucrarse con consciencia y discernimiento en el mundo mediado por contenidos visuales que no son exclusivos de espacios tradicionales como museos o galerías de arte, constituye una postura coherente no solo con el problema y el objetivo del proyecto sino con la teoría relativa tanto al pensamiento crítico como al desarrollo sociocultural del individuo. De acuerdo a Hernández (2005) la visión es útil para aprehender cuestiones relacionadas con temas que van más allá de lo visible (como la divinidad). Una imagen es como un punto atravesado por líneas que van en diferentes direcciones. En las imágenes no solo hay forma, no son percibidas solo por el ojo sino que en ellas hay cargas discursivas que van desde las creencias populares hasta discursos científicos, sociales, políticos y económicos muy elaborados.

\section{Materiales y métodos}

\section{Tipo de estudio:}

El paradigma en el cual se enmarca el proyecto corresponde al paradigma interpretativo. Este paradigma se caracteriza por el giro de la producción del conocimiento frente al paradigma positivista. Se pasa de una forma de conocimiento que busca explicar y controlar los hechos estudiados a una que pretende obtener una comprensión profunda, flexible y como su nombre lo indica, interpretativa de los objetos de estudio. El paradigma interpretativo o modo dos se caracteriza esencialmente porque surge de una necesidad de aplicación en un contexto determinado, es un conocimiento transdisciplinar, heterárquico, transitorio, heterogéneo, socialmente responsable y reflexivo (Gibbons, Limoges, Nowotny, Schwartzman, Scott, \& Trow, 1997).

El proyecto encaja en el paradigma descrito en el párrafo anterior ya que, en primer lugar, busca atender necesidades educativas existentes para un momento histórico específico, en el cual los jóvenes se enfrentan al incremento de la información visual a través de múltiples medios. En segundo lugar, las imágenes que rodean a los estudiantes no provienen de una misma fuente, no todas tienen 
la misma intencionalidad ni impactarán de igual forma a cada individuo, lo cual implica la aceptación de los diferentes rumbos que puedan tomar las conclusiones de este trabajo así como el abordaje del problema desde diferentes perspectivas.

El proyecto cumple con las características establecidas para el enfoque histórico hermenéutico. Por una parte, se encuentra el carácter de la crítica histórica, (Gadamer, 1977), de la investigación, que Vasco (1989) describe como la reconstrucción del pasado y afirma que es tan histórico el momento actual como el tiempo pasado. Por otra parte, al comentar el texto Conocimiento e interés de Habermas, explica el sentido de las hermenéuticas críticas:

La historia y la hermenéutica tratan precisamente de reconstruir todas esas piezas aisladas que aparecen en las diversas interpretaciones de los hechos, en los diversos textos, en las diversas versiones, en los diversos hallazgos arqueológicos, literarios, lingüísticos, para recapturar un "todo-con-sentido". Ese todo-con-sentido es el que da la clave hermenéutica. (Vasco, p. 20)

Para el caso específico de este proyecto, se estudia la relación actual del estudiante con las imágenes que lo circundan cotidianamente, intentando, por medio de preguntas, conocer y como lo indica la cita anterior, reconstruir dicha relación.

El estudio de la información y el abordaje de la educación en arte, parte de la intención de conocer la realidad de los estudiantes, la interpretación y significación que ellos hacen de su entorno visual para, más adelante, aportar herramientas que contribuyan al desarrollo de su criticidad.

El tipo de investigación cualitativa se centra en la comprensión de relaciones, discursos, experiencias o relaciones de carácter subjetivo. Su énfasis de sentido se orienta a penetrar estas realidades con el ánimo de entenderlas más que de aportar datos numéricos. Las relaciones estudiadas no son reproducidas de manera controlada y el investigador se relaciona e identifica los vínculos con el contexto en vez de mantenerse aislado y neutral. En este sentido, el tipo de investigación cualitativa

...pretende llegar a comprender la singularidad de las personas y las comunidades, dentro de su propio marco de referencia y en su contexto histórico-cultural. Se busca examinar la realidad tal como otros la experimentan, a partir de la interpretación de sus propios significados, sentimientos, creencias y valores. (Rodríguez, p. 12)

Este proyecto busca caracterizar e interpretar cualitativamente la información proporcionada por los estudiantes sobre su percepción y experiencia de la educación artística para la identificación del problema. Luego, se busca conocer las características de la relación de los estudiantes participantes con el contexto visual.

Adicionalmente, Hernández, Fernández, \& Baptista (2014) afirman que este tipo de investigación cuenta con un carácter dinámico donde las diferentes fases están en constante interacción afectándose a medida que avanza el proyecto. Este 
carácter dinámico ha sido una característica no planeada durante la ejecución de algunas etapas del proyecto como la definición del problema.

El tipo de diseńo usado en este proyecto se encuentra dentro de la corriente interpretativa y el diseño fenomenológico. Este diseño según Arnal, del Rincón \& Latorre (1994), permite conocer cómo las personas, experimentan e interpretan el mundo social que construyen en interacción. Así, la intención principal ha sido conocer la relación del estudiante con la educación artística, las imágenes visuales y cómo estas relaciones pueden contribuir al desarrollo del pensamiento crítico. (Paul, 2003).

\section{Muestra:}

La población corresponde a estudiantes, hombres y mujeres, de 15 a 17 años de edad de la Institución Educativa Bojacá. La muestra corresponde a los estudiantes de grado décimo, quienes fueron escogidos a conveniencia.

\section{Categorías de análisis:}

Las tres categorías que permitieron el análisis de los resultados y el desarrollo del proyecto son: habilidades de pensamiento crítico, teoría de enseñanza aprendizaje y análisis de la imagen.

\section{Métodos}

En el desarrollo del proyecto se utilizaron las siguientes técnicas de recolección de información: revisión de documentos y entrevista. La revisión documental para Valle (2009) constituye el registro y archivo de aspectos de la vida social. Para el diagnóstico del proyecto se realizó el análisis de la malla curricular de educación artística de la IE Bojacá vigente hasta el 2017, ya que es allí donde se condensa la orientación y comprensión que se tuvo en los últimos ańos sobre la asignatura.

En segundo lugar, con el propósito de recolectar información referente a las actividades, objetivos, evaluaciones e imaginarios entorno a la educación artística de la IE Bojacá, se realizó una entrevista estructurada. De acuerdo a Hernández, Fernández, \& Baptista (2014) el entrevistador realiza su labor siguiendo una guía de preguntas específicas y se sujeta exclusivamente a ésta (el instrumento prescribe qué cuestiones se preguntarán y en qué orden).

Más adelante se volvió a utilizar la entrevista estructurada para recolectar información que permitiera conocer la forma como los estudiantes aplicaban las habilidades de pensamiento crítico a la lectura de imágenes visuales. Dado que no se encontró ninguna prueba que midiera dichas habilidades en el lenguaje visual, se acudió a la teoría y se usó como base para elaborar el instrumento aplicado. 


\section{Resultados}

En primer lugar, al hacer una revisión global de las respuestas obtenidas, se observa que los estudiantes tienen dificultad para expresar por escrito y con claridad su relación con la imagen en terminos formales, discursivos y de relación con su contexto.

La dificultad para realizar una descripción formal de las imágenes presentadas surge a partir de la presencia escasa de elementos conceptuales claros y precisos que permitan describir una imagen en su aspecto mas formal. Un ejemplo de esto es la poca presencia de elementos a observar de manera consciente y su respectiva denominación como la simetría o la profundidad.

Así mismo, la mayor parte de los estudiantes mostraron dificultad para elaborar estructuras semánticas que permitieran describir las imágenes observadas como lo solicitiaba la prueba. En remplazo se acudió a listados de palabras sueltas que no lograron remplazar la construcción de frases con sentido.

Al pasar a la revición específica de cada una de las habilidades de pensamiento crítico definidas para el proyecto y sus correspondientes resultados, se encuentra que el $62 \%$ de los estudiantes encuestados reconoce claramente la intención evocativa de una imagen y el 66\% identifica información relevante de una campaña publicitaria. De lo anterior se deduce que la mayor fortaleza con la que cuentan los estudiantes participantes corresponde a la capacidad para identificar y reconocer información plasmada por medios visuales.

Por otra parte, el $76 \%$ de los estudiantes encuestados se basa en supuestos para establecer la veracidad de una fotografía. Esta ausencia en la búsqueda de información de apoyo o la consulta de fuentes diferentes de los supuestos propios se ubican como la debilidad más recurrente en el grupo.

También se encuentra que el $62 \%$ de los estudiantes encuestados reproduce el mensaje de una campaña publicitaria sin analizar el producto ofertado por esta y el $62 \%$ aunque identifica información de la campaña publicitaria, no establece conclusiones a partir de la confrontación entre la primera información recibida y el producto ofertado, lo cual ubica a esta ausencia de reflexión sobre el mensaje recibido por medios visuales, como la segunda debilidad con mayor frecuencia caracterizadora del grupo.

Los tres puntos señalados en los párrafos anteriores como debilidades fueron utilizados en este proyecto como base para desarrollar una estrategia de enseñanza que contribuya al mitigamiento de dichas dificultades.

\section{Discusión}

Los resultados de la descripción realizada muestran cómo estudiantes que llevan al menos una década de su vida en la escuela y como consecuencia, asistiendo a clases de arte en alguna de sus modalidades, presentan dificultad tanto para 
describir como para generar reflexiones frente a imágenes cotidianas de campañas publicitarias, memes u obras de arte.

Si bien los lineamientos del MEN se encuentran abiertos al desarrollo de competencias comunicativas, las artes plásticas y visuales se han guiado por lo que Hernández en Mejía (2008) llama racionalidad perceptual, expresiva o creativa según el caso. En el imaginario frente a la educación artística se crea la expectativa de elaboración de un producto manual, observable y tangible. Tal vez exista una necesidad de justificar la formación en arte en un mundo que busca resultados tangibles y económicos.

Sin embargo, es importante incluir dentro de la reflexión frente a la formación en la competencia comunicativa no solo la expresión artística, la producción de objetos o el conocimiento de hechos históricos; sino la actitud crítica frente a los ríos de información que trae el momento histórico actual y los retos del ascenso en la comunicación visual tanto en el ámbito educativo como en la vida cotidiana de los jóvenes que asisten a la escuela. Para el siglo XXI no solo se necesitan individuos capaces para producir, sino capaces de desarrollar opiniones fundamentadas y ejecutar acciones coherentes y conscientes frente a cualquier situación. Razones por las cuales preguntarse si vale la pena acoger los llamados de corrientes que propendan por el desarrollo del pensamiento crítico y los estudios de la cultura visual como elementos que ayuden a los individuos a vivir en un mundo donde el sistema económico ejerce presión constante sobre múltiples ámbitos de la vida humana.

\section{Conclusiones}

La primera conclusión de este proyecto atañe a las características del uso de las habilidades de pensamiento crítico en la lectura de imágenes visuales en los estudiantes participantes. La principal fortaleza encontrada corresponde a la habilidad de identificar la intención comunicativa de una imagen, lo cual funciona como base para ejecutar posteriormente otras habilidades del pensamiento más complejas. Los estudiantes identificaron información relevante observando elementos formales de la imagen como colores o materiales usados en la puesta en escena de una fotografía; así como la identificación de información por medio de la evocación de emociones, sentimientos y situaciones.

Por otra parte, se encontraron tres debilidades marcadas en el grupo. En primer lugar la ausencia en el uso de fuentes de información que permitieran enriquecer o corroborar la veracidad de la información extraída de la imagen visual. Solo el 10\% de los estudiantes acudió al texto anexo que aportaba información externa a la imagen visual y el $72 \%$ se basó en supuestos para determinar la veracidad de la misma. Lo anterior afecta la valoración que hace el estudiante de las imágenes observadas ya que dicha valoración se basa en supuestos, no en información confirmada, hecho que podría obstaculizar la construcción de argumentos y posiciones fundamentadas por parte del estudiante. 
Como segunda debilidad se identifica que la relación del estudiante con la información obtenida de la imagen, no está mediada por procesos dialécticos de análisis o reflexión que permitan la reelaboración de ideas o donde se establezca un diálogo entre el sujeto y lo que se observa. El 62\% de los estudiantes reprodujo el mensaje original de la imagen sin problematizar o evidenciar algún tipo de reflexión y la reproducción del mensaje original se realizó literalmente.

En tercer lugar se ubica la dificultad de describir neutralmente elementos constitutivos del objeto visual percibido por los estudiantes; si bien enuncian algunas características generales o llamativas, pasan por alto elementos relativos al contexto, detalles y al establecimiento de categorías.

De los párrafos anteriores se establece la necesidad de fortalecer la habilidad de interpretación y la descripción literal de la imagen; y de diseñar una estrategia de enseñanza que contribuya al desarrollo de las habilidades de análisis, evaluación e inferencia prioritariamente.

Por último, se identifica la necesidad de fortalecer la construcción de secuencias sintácticas escritas que permitan al estudiante expresar con claridad sus respuestas y apreciaciones sobre la imagen.

Como segunda conclusión de este proyecto se determina la utilización de la zona de desarrollo próximo planteada por Vygotsky como el concepto guía para facilitar el fortalecimiento o desarrollo de las habilidades de pensamiento crítico en la clase de educación artística con énfasis en artes plásticas. Para Vygotsky, los procesos psíquicos superiores en principio son externos al individuo y estos corresponden a una construcción social enriquecida por las múltiples experiencias individuales, las cuales sirven como ejemplos facilitadores o referentes en el proceso de aprendizaje individual. Para Vygotsky, el individuo primero encontrará estos procesos desarrollados en los referentes y luego los desarrollará e interiorizará para sí mismo. Así, las imágenes, con finalidad artística o sin ella, tienen una capacidad dual: además de albergar en sí mismas habilidades e información correspondiente al medio en el cual existen, permiten desarrollar las habilidades de que se pretenden fortalecer o desarrollar en este proyecto.

Como tercera conclusión, la estrategia de enseñanza que responde al objetivo de este trabajo y se encuentra en los documentos anexos, se realizó partiendo de las fortalezas identificadas en cuanto al uso de las habilidades de pensamiento crítico en la lectura de imágenes y pretende contribuir a la superación de las debilidades identificadas en la caracterización.

La estrategia planteada presenta un aspecto innovador en la práctica de la institución educativa como se menciona en la justificación de este proyecto. El análisis de la imagen no ha constituido un objetivo ni un enfoque de trabajo, tanto en los documentos de planeación del aula como en la práctica de la clase de educación artística con énfasis en artes plásticas. De acuerdo a los mismos estudiantes y a la malla curricular de la institución, anteriormente la clase se orientó al desarrollo de habilidades manuales y técnicas mientras que, a partir de este proyecto, se plantea una estrategia que busca incluir la reflexión y el análisis de lo visual. 
Con todo lo anterior, se pretende que el estudiante fortalezca o desarrolle según el caso, habilidades de pensamiento crítico como son la interpretación, el análisis, la evaluación, la inferencia y la explicación. Aunque el pensamiento crítico es mencionado en algunos documentos emitidos por el Ministerio de Educación Nacional de Colombia y se menciona en los Lineamientos curriculares de educación artística, su desarrollo es una tarea que ha sido delegada frecuentemente a otros campos del conocimiento, motivo por el cual, este proyecto busca señalar un camino dentro de la educación artística para contribuir al desarrollo intelectual del estudiante desde la reflexión sobre las imágenes y no solo las artes plásticas entendidas como una destreza manual.

\section{Bibliografía}

Acaso, M. (2009). La educación artística no son manualidades. Nuevas practicas en la enseñanza de las artes y la cultura visual. Madrid, España: Los libros de la catarata.

Adorno, T. W. (1966, abril 18). Retrieved abril 5, 2019, from http:// zeitgenoessischeaesthetik.de/wp-content/uploads/2013/07/la-educacion-después-deAuschwitz-TheodorWAdorno.pdf

Adorno, T. W. (1998). Educación para la emancipación. Madrid, España: Ediciones Morata.

Arnal, J., del Rincón, D., \& Latorre, A. (1994). Investigación educativa. Fundamentos y metodología. Barcelona: Editorial Labor.

Barragán, R., \& Gómez, W. (2012). EL lenguaje de la imagen y el desarrollo de la actitud crítica en el aula: propuesta didáctica para la lectura de signos visuales. Íkala, revista de lenguaje y cultura, 17 (1), 79-92.

Barragán, A. P., Plazas, N. I., \& Ramírez, G. A. (2016). La lectura de imágenes: una herramienta para el pensamiento crítico. Educación y ciencia, 19, 85-103.

Bauman, Z. (2007). Los retos de la educación en la modernidad líquida. (G. S.A., Ed.) Barcelona, España: Editorial Gedisa S.A.

Calaf, R., \& Fontal, O. (2010). Cómo enseñar arte en la escuela. Madrid, España: Editorial Sintesis.

Calvino, I. (2000). Seis propuestas para el próximo milenio. (E. Siruela, Ed., \& A. Hernández, Trans.) Madrid, España: Palomar.

Cernas, M., Márquez, C. V., \& Abarca, M. S. El arte como herramienta para favorecer el desarrollo de pensamiento crítico en preescolares. Revista internacional de educacion preescolar e infantil, 1 (2), 47-55.

Facione, P. A. (2007). http://www.eduteka.org/PensamientoCriticoFacione.php. Retrieved from http://www.eduteka.org/PensamientoCriticoFacione.php 
Fajardo, E. (2018, enero/junio). Equidad y calidad educativa en America Latina: responsabilidades, logros, desafios e inclusión. (S. e. Atlántico, Ed.) Retrieved junio 7, 2019, from https://investigaciones.uniatlantico.edu.co/revistas/index.php: https:/www.google.com/ search?client $=$ safari $\& \mathrm{rls}=$ en $\& \mathrm{q}=$ Equidad $+\mathrm{y}+$ calidad + educativa $+\mathrm{en}+\mathrm{Ame} \% \mathrm{CC} \% 81 \mathrm{rica}+\mathrm{La}-$ tina:+responsabilidades, +logros, +desafi $\% \mathrm{CC} \% 81 \mathrm{os}+\mathrm{e}+$ inclusio $\% \mathrm{CC} \% 81 \mathrm{n}+$ Ernesto $+\mathrm{Fa}-$ jardo+Pascagaza+ernestofajardo@usantotomas.edu.co\&ie=UTF-8\&oe=UTF-8

Gadamer, H., (1997), El giro hermenéutico. Madrid: Cátedra.

García, H. Y. (2012). La mirada engendra nuevas formas de pensar. Praxis \& saber, 3 (6), 191-212

González, J. H. (2006). Discernimiento. Cali, Colombia: Universidad Icesi.

Habermas, J. (1982). Conocimiento e interés. Madrid, España: Taurus.

Habermas, J., 1989: Identidades nacionales y postnacionales. Madrid: Tecnos

Hernández, F. (2005, jul/dez). ¿De qué hablamos cuando hablamos de cultura visual? Educaçao e realidade, pp. 9-34.

Hernandez, F. (2010). Educación y cultura visual. Barcelona, España: Ediciones Octaedro. Hernández, R., Fernández, C., \& Baptista, M. (2014). Metodología de la investigación. México D.F.: McGraw Hill.

Luna, C. (2015). El futuro del aprendizaje 2. Investigación y prospectiva en educaciónDocumentos de trabajo, 14.

Mejía, S. (2008). La educación artística como comprensión crítica de la cultura visual en Fernando Hernández. (Pensamiento), (palabra)... y oBra, 36 - 46.

MEN. (2000). Lineamiento curriculares educación artistica. Retrieved abril 5, 2019, from https://www.mineducacion.gov.co/1621/articles-339975_recurso_4.pdf

MEN. (2010). Orientaciones pedagógicas para la educación artística básica y media.

Ministerios de Cultura y Educación de Colombia, Oficina Regional de Cultura para América Latina y el Caribe de la UNESCO. (2005, noviembre 15). www.lacult.unesco. org. Retrieved mayo 3, 2019, from Conferencia regional de América Latina y el Caribe, preparatoria de la Cumbre Mundial de Educación Artística: documento base. Bogotá: http://www.lacult.unesco.org/noticias/showitem.php?id=372

Ministerio de Educación Nacional de Colombia. (2010). www.mineducación.gov. co. Retrieved mayo 3, 2019, from https://www.mineducacion.gov.co/1759/w3article-241907.html?_noredirect $=1$

Morales, L. (2014). El pensamiento critico en la teoría educativa contemporánea. Actualidad investigativa en Educación, 14(2), 4-23. doi:10.15517/aie.v14i2.14833 
Nussbaum, M. (2010). Sin fines de lucro. Buenos Aires: Katz editores.

Osorio, S. N. (2007). La teoría crítica de la sociedad de la Escuela de Frankfurt. Revista Educación y desarrollo social, 1, 104-119.

Parra, E., \& Lago de Vergara, D. (2003). Didáctica para el desarrollo del pensamiento crítico en estudiantes Universitarios. Educación Médica Superior, 17(2). Recuperado de http:// scielo.sld.cu/scielo.php?script=sci_arttext \&pid=S0864-21412003000200009

Paul, R., \& Elder, L. (2003). Una mini-guia para el pensamiento critico, conceptos y herramientas. Recuperado de https://www.criticalthinking.org/resources/PDF/SPConceptsandTools.pdf

Peeler, D. (2016). The importance of critical thinking: A cost management and Budget Slant. The journal of the American Society of Military Comptrollers. 61(2), 30-32. Recuperado de https://www.thefreelibrary.com/The+importance+of+critical+thinking\%3A+a+cos$\mathrm{t}+$ management+and+budget...-a0457394294

Polidori, A., \& Mier, R. (2017). Nicht für immer! ¡no para siempre! (Vol. 1). (A. Polidori, $\&$ R. Mier, Eds.) México DC, México: Editorial Gedisa S.A.

Rodriguez, M. d., \& Diaz. (2012). Pensamiento crítico y aprendizaje. México, México: Editorial Limusa.

Scott, C. (2015, noviembre). El futuro del aprendizaje 2 ¿Qué tipo de aprendizaje se necesita en el siglo XXI? Documentos de trabajo. Investigación y Prospectiva en Educación UNESCO, 14.

Valles, M. (2009). Técnicas cualitativas de investigación social. Madrid: Editorial Síntesis S.A.

Vélez, C. F. (2013). Una reflexion interdisciplinar sobre el pensamiento crítico. Revista latinoamericana de estudios educativos, 9, 11-39.

Vigotsky. (1995). Pensamiento y lenguaje. Ediciones Fausto.

Virilio, P. (1998). La máquina de visión. (M. A. Rato, Trans.) Madrid, España: Editiones Cátedra S.A.

Zamora, J. A. (2009). Th. Adorno: aportaciones para una teoría crítica de la educación. Teoria educativa, 21 (1), 19-48. 